This document is published in:

Materials Characterization, vol. 95 (Sep. 2014), pp. 105-117

DOI: http://dx.doi.org/10.1016/i.matchar.2014.06.011

(C) 2014 Elsevier Inc. 


\section{Highlights}

Effect of processing conditions on microstructural features in $\mathrm{Mn}-\mathrm{Si}$ sintered steels

Raquel Oro, ${ }^{\mathrm{a}, *}$, Eduard Hryha ${ }^{\mathrm{a}}$, Mónica Campos ${ }^{\mathrm{b}}$, José M. Torralba ${ }^{\mathrm{b}, \mathrm{c}}$

${ }^{a}$ Department of Materials and Manufacturing Technology, Chalmers University of Technology, Rännuägen 2A, SE-41296 Gothenburg, Sweden

${ }^{\mathrm{b}}$ Department of Materials Science and Engineering, IAAB, Universidad Carlos III de Madrid, Av. Universidad 30, 28911 Leganés, Madrid, Spain

'IMDEA Materials Institute, c/Eric Kandel, 2, 28906 Getafe, Madrid, Spain

- Oxide distribution in steels containing oxidation-sensitive elements

- Mn, Si introduced in a master alloy powder, mixed with a base iron powder

- Selective oxidation of Mn and Si on iron grain boundaries

- Decohesive fracture caused by degradation of grain boundaries by oxide inclusions

- Reducing agents efficient at low temperatures critical for avoiding oxide inclusions 


\title{
Effect of processing conditions on microstructural features in Mn-Si sintered steels
}

\author{
Raquel Oro ${ }^{a, *}$, Eduard Hryha ${ }^{a}$, Mónica Campos ${ }^{b}$, José M. Torralba ${ }^{b, c}$ \\ ${ }^{a}$ Department of Materials and Manufacturing Technology, Chalmers University of Technology, Rännuägen 2A, SE-41296 Gothenburg, Sweden \\ ${ }^{b}$ Department of Materials Science and Engineering, IAAB, Universidad Carlos III de Madrid, Av. Universidad 30, 28911 Leganés, Madrid, Spain \\ 'IMDEA Materials Institute, c/Eric Kandel, 2, 28906 Getafe, Madrid, Spain
}

\section{A R T I C L E D A T A}

Article history:

Received 25 February 2014

Received in revised form 3 June 2014

Accepted 10 June 2014

Keywords:

Powder metallurgy

Master alloys

Fe-Mn-Si-C

Oxygen-sensitive elements

Processing conditions

Sintering behavior

\begin{abstract}
A B S T R A C T
Sintering of steels containing oxidation sensitive elements is possible if such elements are alloyed with others which present lower affinity for oxygen. In this work, a master alloy powder containing Fe-Mn-Si-C, specifically designed to create a liquid phase during sintering, has been used for such purpose. The effect of processing conditions such as sintering temperature and atmosphere was studied with the aim of describing the microstructural evolution as well as the morphology and distribution of oxides in the sintered material, evaluating the potential detrimental effect of such oxides on mechanical properties.

Chemical analyses, metallography and fractography studies combined with X-ray photoelectron spectroscopy analyses on the fracture surfaces were used to reveal the main mechanism of fracture and their correlation with the chemical composition of the different fracture surfaces. The results indicate that the main mechanism of failure in these steels is brittle fracture in the surrounding of the original master alloy particles due to degradation of grain boundaries by the presence of oxide inclusions. Mn-Si oxide inclusions were observed on intergranular decohesive facets. The use of reducing atmospheres and high sintering temperatures reduces the amount and size of such oxide inclusions. Besides, high heating and cooling rates reduce significantly the final oxygen content in the sintered material. A model for microstructure development and oxide evolution during different stages of sintering is proposed, considering the fact that when the master alloy melts, the liquid formed can dissolve some of the oxides as well as the surface of the surrounding iron base particles.
\end{abstract}

(C) 2014 Published by Elsevier Inc.

\section{Introduction}

Alloying elements such as $\mathrm{Mn}$ and $\mathrm{Si}$ provide significant improvement of wrought steel properties and present high availability at a low cost. However, their sensitivity for oxygen brings up an important technological challenge for the powder metallurgy (PM) route, where the very large specific surface of the starting powders makes them more reactive in contact with the surrounding atmosphere. One of the possible ways for introducing these elements in sintered steels is to produce a master alloy powder in which the oxidation sensitive elements are alloyed with others presenting lower affinity for oxygen [1-4].

Fe-Mn-Si master alloys were introduced for the first time in sintered steels during the early 80 s and were found to provide surprisingly good mechanical properties in as-sintered steel [5-7]. With an ultimate tensile strength of $1000 \mathrm{MPa}$, an

\footnotetext{
* Corresponding author.

E-mail addresses: raqueld@chalmers.se (R. Oro), hryha@chalmers.se (E. Hryha), campos@ing.uc3m.es (M. Campos), torralba@ing.uc3m.es, josemanuel.torralba@imdea.org (J.M. Torralba).
} 
elongation of about $3 \%$ and only a slight shrinkage of $0.06 \%$, these steels presented properties that belonged to the best data available on comparable materials in the as-sintered condition. Moreover, the appropriate combination of $\mathrm{Mn}$ and Si provided accurate dimensional control of the sintered parts. However, in spite of the promising results obtained, Fe-Mn-Si master alloys were never considered for industrial use, mainly due to their high sensitivity to different processing conditions.

In order to present the Fe-Mn-Si master alloys as a real alternative for the PM-market, the specific requirements for processing these steels must be stated and the different phenomena taking place during sintering as well as their possible influence in the final performance must be clearly described.

Recent studies on steels containing Fe-Mn-Si master alloys (gas atomized in $\mathrm{N}_{2}$ ) have shown that these materials require the use of very high sintering temperatures (over $1300^{\circ} \mathrm{C}$ ) to reduce the highly stable $\mathrm{Mn}-\mathrm{Si}$ oxides [8,9]. Besides, when the master alloy is mixed with an iron base powder, the heterogeneity in chemical activity between the different components of the mix presents further risks for oxidation. Reduction of oxides with lower stability (such as the easily reducible iron oxides covering the surface of the iron base powder), at temperatures at which $\mathrm{Mn}$ and Si are still avid for oxygen, can lead to an oxygen transfer from the surface of the iron base powder to the oxidation-sensitive elements available on the surface of the master alloy powder particles. The master alloy is therefore acting as an "internal-getter agent" $[9,10]$.

In this work, the sintering behavior is evaluated not only from the point of view of oxide removal but also considering the location and morphology of remaining oxides and their potential effect on mechanical properties. By combining fracture analyses with microstructural evaluation a model for the microstructure development and oxide evolution is proposed, taking into account the effect of liquid phase formation.

\section{Materials and experimental procedure}

\subsection{Processing of sintered steels modified with master alloy additions}

Sintered steels with nominal composition Fe-1.6Mn-0.6Si$0.64 \mathrm{C}$ (wt.\%) were obtained through the master alloy route. Master alloy powder - with composition Fe-40Mn-15Si-1C (wt.\%) - was gas atomized in $\mathrm{N}_{2}$ (purity $99.9 \%$ ) using a lab scale atomizer (Atomizing System LTD). Impact test bars were produced pressing at $600 \mathrm{MPa}$ a mix containing water atomized iron powder, master alloy, natural graphite, and lubricant in the amounts indicated in Table 1.

Before sintering, delubrication of green compacts was accomplished in a tubular laboratory furnace at $600{ }^{\circ} \mathrm{C}$ for 10 min in $\mathrm{N}_{2}$ atmosphere (purity 99.9\%).

Different sintering conditions were applied depending on the type of experiment proposed (Table 2):

- Experiment A is designed to evaluate the effect of sintering temperature. Sintering is carried out in a lab scale furnace

\begin{tabular}{|c|c|c|}
\hline Materials & Characteristics & $\begin{array}{l}\text { Addition } \\
\text { (wt.\%) }\end{array}$ \\
\hline $\begin{array}{l}\text { Water atomized } \\
\text { iron powder }\end{array}$ & $\begin{array}{l}\text { Grade ASC } 100.29 \text { from } \\
\text { Höganäs AB, Sweden } \\
O<0.1 \text { wt.\%, C }<0.01 \text { wt.\%, } \\
d_{50} \sim 75 \mu \mathrm{m}\end{array}$ & Bal. \\
\hline Master alloy & $\begin{array}{l}\text { Fe-40Mn-15Si-1C (wt.\%), } \\
\mathrm{d}_{50} \sim 17 \mu \mathrm{m}, \mathrm{d}_{90} \sim 43 \mu \mathrm{m}\end{array}$ & 4 \\
\hline Natural graphite & Grade UF4, Kropfmühl & 0.6 \\
\hline Lubricant & Amide wax & 0.6 \\
\hline
\end{tabular}

in reducing atmosphere $\left(\mathrm{N}_{2-1}-10 \mathrm{H}_{2}-0.1 \mathrm{CH}_{4}\right)$ and simulating the conditions typically used in industry.

- Experiment B is aimed to define the effect of processing atmosphere when sintering at high temperature $\left(1300^{\circ} \mathrm{C}\right)$. These samples were sintered in a dilatometer under either inert (Ar) or reducing $\left(\mathrm{H}_{2}\right)$ atmosphere.

In the lab furnace AHT Silitstabofen used in Experiment A, the gas flow was introduced from the furnace outlet and the samples were progressively pushed to the maximum temperature zone where they were kept for $60 \mathrm{~min}$. This procedure is used to simulate the process in an industrial belt furnace. After sintering, the samples were cooled at approximately $0.75^{\circ} \mathrm{C} / \mathrm{s}$, in a water-jacketed exit zone under the same protective atmosphere.

\subsection{Chemical analyses}

Chemical analyses were carried out to study the effect of temperature and atmosphere on the final content of interstitial elements. Sintered samples were manually dry-cut in pieces of approximately $600 \mathrm{mg}$. Oxygen and nitrogen were measured with a LECO-TC500 equipment, and carbon and sulfur were analyzed using a LECO-CS200. At least 4 pieces of the same material were measured to obtain a mean value and the corresponding standard deviation of each measurement.

\subsection{Metallography and fractography}

Cross section of the samples was observed by optical microscopy and SEM. The scanning electron microscope used is a Philips XL-30 equipped with an EDAX probe (Energy Dispersive Analysis of X-rays - EDAX-DX4). Specimens were prepared following the conventional metallographic process. Etching was carried out combining two different etching agents:

- Firstly with $10 \mathrm{~g}$ of potassium meta-bisulfite and $100 \mathrm{ml}$ of distilled water for $15 \mathrm{~s}$. This etchant allowed to reveal the microstructure without dissolving oxide inclusions during etching, as indicated by $[11,12]$.

- Secondly with a mix (1:1) of Picral $4 \%$ and $\mathrm{Na}_{2} \mathrm{SO}_{4}$ solution ( $1 \mathrm{~g} \mathrm{Na}_{2} \mathrm{SO}_{4}$ and $100 \mathrm{ml}$ distilled water) for $1 \mathrm{~s}$. This second etching agent proposed helps to emphasize the differences between bainite and martensite [13].

Fracture surfaces were examined using a scanning electron microscope LEO 1550 Gemini, equipped with an EDX analyzer 
Table 2 - Sintering conditions applied to steels modified with master alloy additions.

\begin{tabular}{ccccc} 
Experiment & Sintering device & Sintering temperature $\left({ }^{\circ} \mathrm{C}\right)$ & Atmosphere & Heating and cooling rate $\left({ }^{\circ} \mathrm{C} / \mathrm{s}\right)$ \\
\hline \multirow{2}{*}{ A } & Lab furnace AHT Silitstabofen & 1120 & $\mathrm{~N}_{2}-10 \mathrm{H}_{2}-0.1 \mathrm{CH}_{4}($ vol.\%) & Heating: 1.3 \\
& & 1250 & $\mathrm{Ar}$ & Cooling: $~ 0.75$ \\
B & Netzsch 402 ES dilatometer & 1300 & $\mathrm{Ar}$ & 0.17 \\
& & & $\mathrm{H}_{2}$ & \\
\end{tabular}

INCA X-sight (Oxford Instruments Ltd.) which provides semiquantitative information about the chemical composition of the sample in specific points or areas.

\subsection{X-ray photoelectron spectroscopy (XPS) analyses}

With the aim of detecting the species present on the fracture surfaces, sintered steels were fractured in a fracture-unit coupled to the XPS chamber. This device allows the transport in ultra high vacuum, making sure that the fracture surface is not in contact with the atmosphere before the analysis. Surface chemical analyses were carried out by means of X-ray photoelectron spectroscopy (XPS) using a PHI 5500 instrument. Identification of the chemical species present on the fracture surfaces is possible by performing survey scans over a wide range of binding energies (0-1100 eV). The surface composition was estimated by curve fitting the characteristic peaks and converting their intensity into apparent atomic concentration by the use of standard relative sensitivity factors [14]. Determination of the chemical state of each element is possible by the use of narrow scans with high energy resolution over the binding energy ranges characteristic for the elements of interest. Besides, depth profiles were obtained by sputtering of the analyzed surface with $\mathrm{Ar}+$ ions to controlled depths and analyzing the etched surface. The etching rate was calibrated using flat oxidized tantalum foil $[15,16]$ with the known oxide thickness. Hence, etch depth is presented in tantalum oxide units that is close to the etching behavior of metallic oxides of interest.

\section{Results and discussion}

\subsection{Chemical analyses}

Chemical content in interstitial elements ( $\mathrm{C}, \mathrm{S}, \mathrm{O}$, and $\mathrm{N}$ ) was measured in the two main constituents of the mix: iron base and master alloy powders (Table 3). These values are used as a reference for evaluating the efficiency of the different oxidation/reduction processes during sintering.

As it is observed in Table 3, iron base powder, which is the main constituent of the green compacts, presents the highest oxygen content, considerably higher than that in the master alloy powder. Therefore, the iron base powder itself will be an important source of oxygen during sintering.

Previous studies on low alloy sintered steels have indicated that reduction of iron oxides in the presence of $\mathrm{H}_{2}$ takes place at temperatures of approximately $400{ }^{\circ} \mathrm{C}, \mathrm{H}_{2}$ being the most effective reducing agent at the lower temperatures of the sintering cycle. Reduction of more stable oxides or internal oxides necessarily takes place at higher temperatures at which carbothermal reduction is the main mechanism [17-19]. Oxygen values in sintered steels (Table 4) show how reduction of oxides is enhanced either by the increase of sintering temperature (samples sintered at $1250^{\circ} \mathrm{C}$ in Experiment A) or by the use of reducing atmospheres (samples sintered in $\mathrm{H}_{2}$ in Experiment $\mathrm{B}$ ).

Increasing the sintering temperature from $1120^{\circ} \mathrm{C}$ to $1250^{\circ} \mathrm{C}$, oxygen content decreases drastically (4 times less), suggesting that carbothermal reduction is critical for enhancing oxide removal in these steels. The fact that the carbon content in samples sintered at $1120^{\circ} \mathrm{C}$ (0.6 wt.\%) is only slightly lower than the total carbon introduced in the initial mix (0.64 wt.\%) indicates that carbothermal reduction is still not activated at this temperature due to the presence of stable oxides. Effective carbothermal reduction of oxides at higher sintering temperatures $\left(1250^{\circ} \mathrm{C}\right)$ leads to significantly lower oxygen content and consequently higher carbon losses.

The effect of the sintering atmosphere is evidenced in Experiment B. When sintering in Ar, where carbon is the only reducing agent available, the final oxygen content is significantly higher than in $\mathrm{H}_{2}$. In fact, oxygen content in samples sintered in $\operatorname{Ar}(0.074 \mathrm{wt} . \%)$ is only slightly lower than in the starting iron base powder (0.1 wt.\%), suggesting a poor oxide removal even at the high sintering temperatures applied $\left(1300^{\circ} \mathrm{C}\right)$. This is most likely a consequence of a transformation of oxides in the intermediate temperature range of the sintering cycle. Carbothermal reduction of iron oxides (the less stable oxides in the system) requires sintering temperatures around $700{ }^{\circ} \mathrm{C}$. At these temperatures, reduction of iron oxides can lead to oxidation of $\mathrm{Mn}$ and $\mathrm{Si}$ in such a way that there is a minor loss of oxygen but strong transfer from the iron base powder to the surface of the master alloy particles ("internal-getter effect" $[9,10,20])$. This effect is somehow avoided by sintering in $\mathrm{H}_{2}$, since reduction of iron oxides

Table 3 - Interstitial contents in master alloy powder and iron base powder.

\begin{tabular}{lcccc}
\multicolumn{1}{c}{ Material } & $\mathrm{O}($ wt.\%) & $\mathrm{N}($ wt.\%) & $\mathrm{C}$ (wt.\%) & $\mathrm{S}($ wt.\%) \\
\hline $\begin{array}{l}\text { Iron base powder } \\
\begin{array}{l}\text { ASC 100.29 } \\
\text { Master alloy powder } \\
\text { Fe-40Mn-15Si-1C }\end{array}\end{array}$ & $0.10 \pm 0.02$ & $0.003 \pm 0.001$ & $0.005 \pm 0.004$ & $0.010 \pm 0.001$ \\
\hline
\end{tabular}


Table 4 - Interstitial contents in sintered steels modified with master alloy additions.

\begin{tabular}{lcccrr}
\multicolumn{2}{c}{ Sintering conditions } & O (wt.\%) & N (wt.\%) & C (wt.\%) & S (wt.\%) \\
\hline \multirow{2}{*}{ Experiment A } & $1120^{\circ} \mathrm{C}$ & $0.054 \pm 0.003$ & $0.038 \pm 0.001$ & $0.60 \pm 0.01$ & $0.008 \pm 0.001$ \\
& $1250{ }^{\circ} \mathrm{C}$ & $0.015 \pm 0.001$ & $0.041 \pm 0.001$ & $0.52 \pm 0.02$ & $0.008 \pm 0.001$ \\
Experiment B & $\mathrm{Ar}$ & $0.074 \pm 0.006$ & $0.0015 \pm 0.0005$ & $0.54 \pm 0.07$ & $0.017 \pm 0.006$ \\
& $\mathrm{H}_{2}$ & $0.035 \pm 0.004$ & $0.0009 \pm 0.0002$ & $0.49 \pm 0.02$ & $0.014 \pm 0.004$ \\
\hline
\end{tabular}

takes place at lower temperatures $\left(400^{\circ} \mathrm{C}\right)$ at which the reactivity of the oxidation sensitive elements is still low.

When sintering in $\mathrm{H}_{2}$, carbothermal reduction is complemented by reduction with $\mathrm{H}_{2}$, and therefore, less decarburization would be expected. However, carbon content measured in samples sintered in $\mathrm{H}_{2}$ is slightly lower than in Ar. This effect has never been observed in Fe-C steels, therefore its presence in steels containing Fe-Mn-Si master alloy was attributed to a possible recombination of oxygen with the oxygen-sensitive elements following the reaction in Eq. (1). Thermodynamic viability of this reaction increases for metallic elements with high affinity for oxygen, and is especially important when considering the formation of $\mathrm{SiO}_{2}$. Methane generation by this reaction is apparently the reason for the higher decarburization in $\mathrm{H}_{2}$ atmospheres [8,9]. Besides, the oxygen content after sintering in $\mathrm{H}_{2}$ in the dilatometer is rather high (0.035 wt.\%) compared for instance with $\mathrm{Cr}$ containing steels sintered in similar conditions ( 0.01 wt.\%) [21], which might also be a consequence of a re-oxidation through reaction in Eq. (1).

$(\mathrm{x} / \mathrm{y}) \cdot \mathrm{Me}+2 \mathrm{H}_{2}+\mathrm{CO}=\mathrm{CH}_{4}+1 / \mathrm{y} \cdot \mathrm{Me}_{\mathrm{x}} \mathrm{O}_{\mathrm{y}}$.

Sulfur content after sintering is very similar in all samples (regardless the sintering conditions used) and is approximately equal to initial sulfur content in the iron base powder (Table 3). This suggests that iron base powder might be the main source of sulfur and, during sintering, sulfur is not eliminated from the sample, but only redistributed and/or recombined.

Slight nitrogen pick up is detected in samples from Experiment $\mathrm{A}$ as a consequence of using a nitrogen-based atmosphere for sintering.

Comparing the results obtained in both experiments, oxygen contents obtained in Experiment B are surprisingly high for the sintering temperatures applied $\left(1300^{\circ} \mathrm{C}\right)$, as a consequence of the low heating and cooling rates used $\left(0.17^{\circ} \mathrm{C} / \mathrm{s}\right)$. When sintering steels containing elements with a high affinity for oxygen, there is a range of temperatures $\left(600-1000{ }^{\circ} \mathrm{C}\right)$ where the conditions are reducing for iron but strongly oxidizing for the oxygen-sensitive elements. Therefore, larger content of thermodynamically stable oxides is formed at low heating rates. The use of higher heating rates, specifically in this range of temperatures, reduces importantly the risk of oxygen transfer, and therefore the amount of oxygen that is "trapped" in the material.

\subsection{Microstructure, fractography and surface analyses}

\subsubsection{Experiment A: effect of sintering temperature}

The development of different microstructures in steels modified with master alloy additions is strongly affected by the formation of a liquid phase. In particular, the master alloy used in this study was specifically designed to have a melting point below $1100{ }^{\circ} \mathrm{C}$. Previous studies with this same master alloy powder have shown that its melting range is not significantly affected by the interaction with carbon added as graphite or with the iron base powder, at least for the steel composition considered in this study [22]. The liquid phase formed is able to dissolve partly the surface of the iron base powder, which causes an improvement in its wetting behavior and hinders the access of the liquid to the surrounding pore channels. The dissolutive interaction between liquid and iron base particles and the subsequent solidification of liquid saturated in iron leaves highly alloyed areas concentrated in the vicinity of original master alloy particles.

An increase in the sintering temperature from 1120 to $1250^{\circ} \mathrm{C}$ facilitates complete melting of master alloy particles and provides broad highly alloyed areas due to the enhanced diffusion of alloying elements (Fig. 1). Areas with high concentration of alloying elements present martensitic microstructures. Especially in steels sintered at $1250^{\circ} \mathrm{C}$, transgranular nucleation of grains with acicular morphology is observed in these martensitic areas, which might correspond to bainite or acicular ferrite grains.

Nucleation of acicular ferrite grains has been reported to be promoted by the presence of non-metallic inclusions with high sulfide capacity, particularly with mixed $\mathrm{Mn}-\mathrm{Si}$ oxides $\left(\mathrm{MnSiO}_{3}\right.$ or $\left.\mathrm{Mn}_{2} \mathrm{SiO}_{4}\right)[23,24]$. Sulfur is dissolved in the oxide inclusion at high temperatures, and precipitates during cooling forming a MnS layer on the oxide surface. This creates a Mn depleted zone in the surrounding of the oxide that can promote nucleation of acicular ferrite $[11,12,23,24]$. Besides, it must be considered that, apart from $\mathrm{Mn}$, these areas are also highly alloyed with $\mathrm{Si}$, which is a strong stabilizer of ferrite.

In samples sintered at $1120^{\circ} \mathrm{C}$ the grain boundaries of the particles located in the vicinity of the master alloy are degraded by the presence of oxides (Fig. 1). An increase in the sintering temperature enhances both oxide reduction and solid diffusion and therefore stronger contacts between particles and more rounded porosity are observed.

Due to the dissolutive interaction between liquid phase and solid iron powder, there is a compositional gradient in the area surrounding primary master alloy particles (line scan in Fig. 2) where the concentration of $\mathrm{Mn}$ and $\mathrm{Si}$ decreases continuously from approximately $8 \mathrm{wt} . \% \mathrm{Mn}-3 \mathrm{wt} . \% \mathrm{Si}$ to 0.5 wt.\% Mn-0.5 wt.\% Si in the first $40 \mu \mathrm{m}$ (for a sintering temperature of $1120^{\circ} \mathrm{C}$ ).

Pores left after melting and dissolution of master alloy particles are found to be covered by an inhomogeneous oxide layer with gray contrast in the back scattered electron image (Area A in Fig. 2). EDS analysis of this area reveals high oxygen content and considerably high content of $\mathrm{Mn}$ and $\mathrm{Si}$, which are 

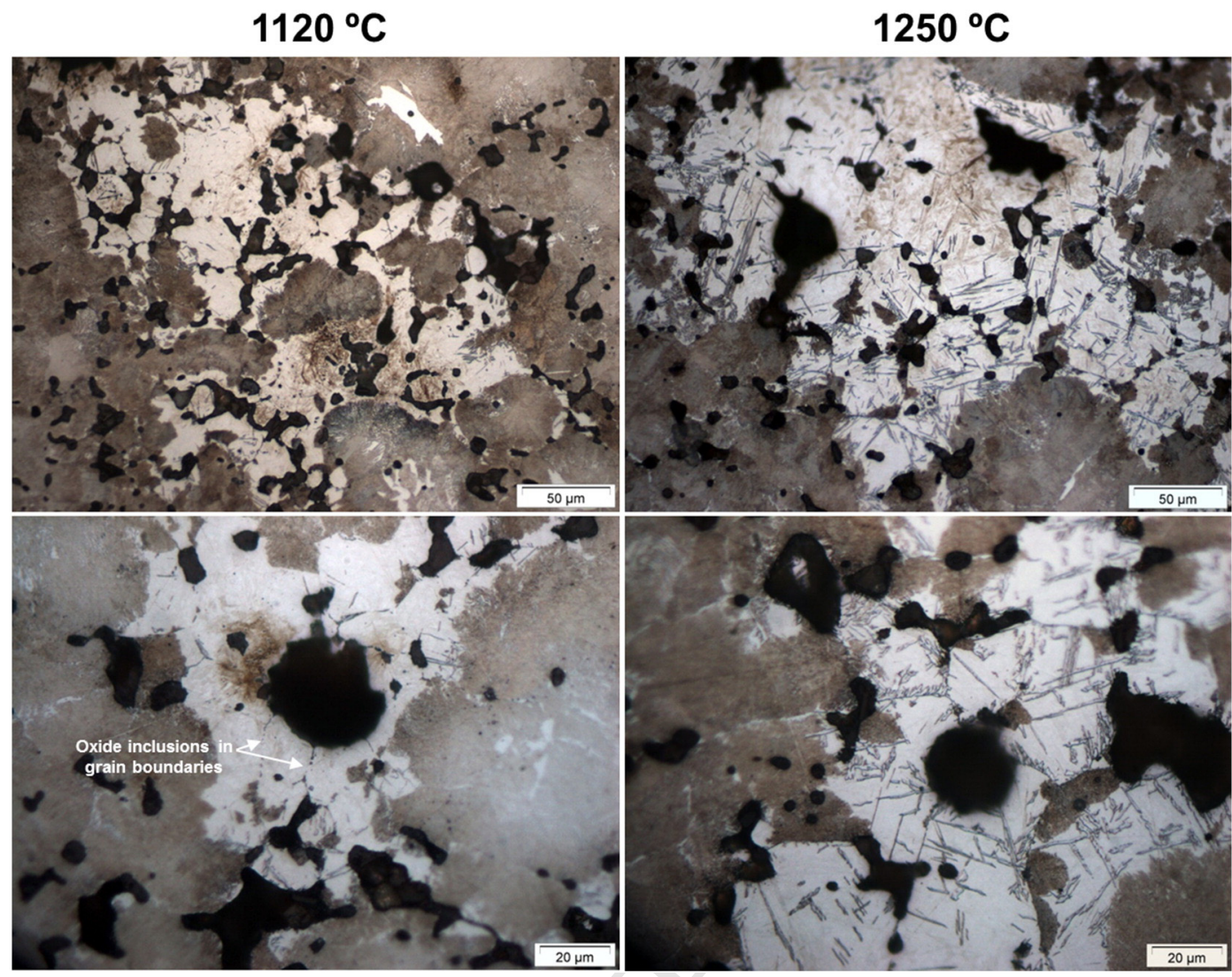

Fig. 1 - Microstructure of steels sintered in a lab furnace for $1 \mathrm{~h}$ in $\mathrm{N}_{2}-10 \mathrm{H}_{2}-0.1 \mathrm{CH}_{4}$ at $1120^{\circ} \mathrm{C}$ (left) and $1250{ }^{\circ} \mathrm{C}$ (right).

present in a relative atomic concentration close to $1 / 1$. This suggests that selective oxidation of $\mathrm{Mn}$ and $\mathrm{Si}$ causes the formation of mixed $\mathrm{Mn}-\mathrm{Si}$ oxides, most likely the type $\mathrm{MnSiO}_{3}$.
Even though $\mathrm{MnSiO}_{3}$ oxide is less stable than $\mathrm{SiO}_{2}$ oxides, 345 previous studies have shown that when the $\mathrm{Si} / \mathrm{Mn}$ weight 346 ratio in the steel matrix is below (or close to) $1 / 1$-as is the case 347
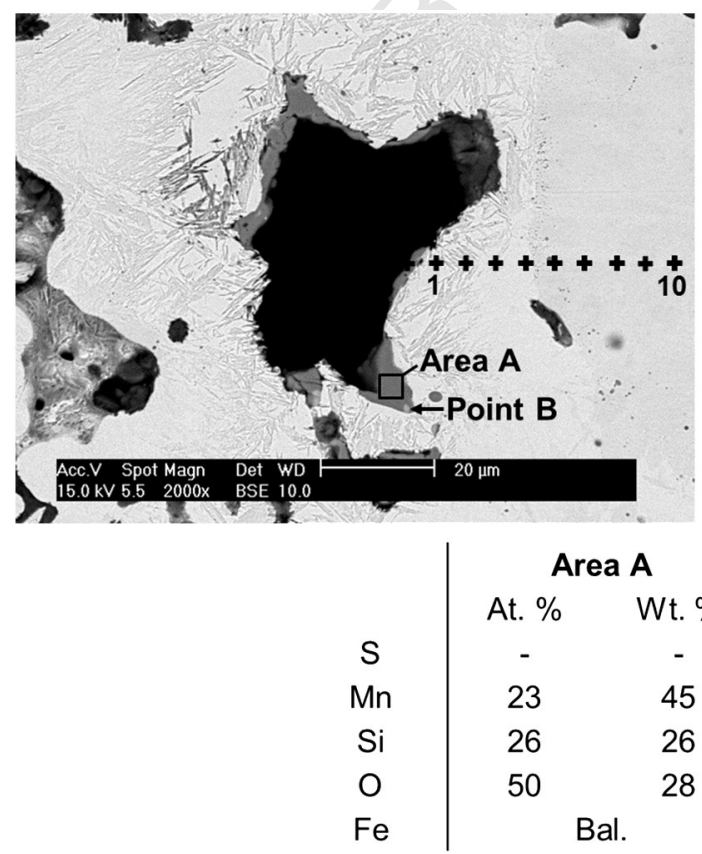

Area A At. $\% \quad$ Wt. $\%$ - $\quad-$ $23 \quad 45$ $26-26$ 50 Bal.

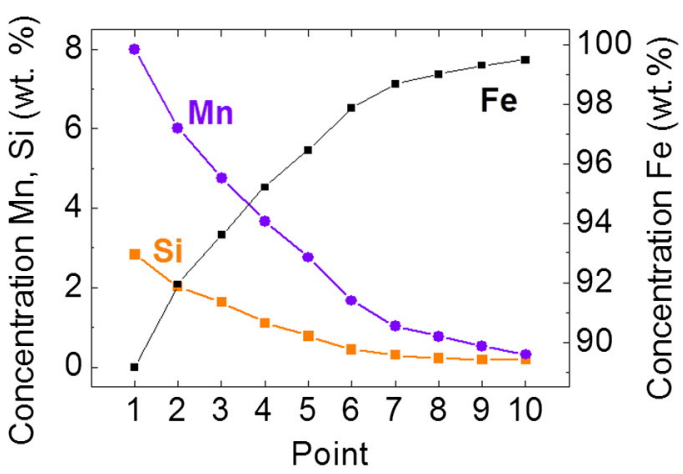

Point B At. $\% \quad$ Wt. $\%$ $31 \quad 27$ $36 \quad 55$

$7 \quad 6$

25

Bal.

Fig. 2 - SEM + EDS analysis of the cross sections of samples sintered in $\mathrm{N}_{2}-10 \mathrm{H}_{2}-0.1 \mathrm{CH}_{4}$ at $1120{ }^{\circ} \mathrm{C}$. 
of the steels studied here-mixed $\mathrm{Mn}-\mathrm{Si}$ oxides are predominantly formed [25-28].

Formation of a sulfide layer on the surface of such oxides is observed in specific areas (Point B in Fig. 2), where EDS analysis revealed very high $\mathrm{Mn}$ and S content. Such sulfide layers are typically found in association with mixed $\mathrm{Mn}-\mathrm{Si}$ oxides [23,24].

Fig. 2 evidences the presence of Mn-Si oxides with MnS layers on the surface, which as previously discussed, are supposed to facilitate the formation of acicular ferrite. Due to the enhanced sulfur segregation at such higher temperatures, this acicular ferrite grains are predominantly present in steels sintered at $1250^{\circ} \mathrm{C}$.

Analyses of the fracture surfaces provide information about the fracture micro-mechanisms and allow describing the morphology and distribution of the oxides. For both sintering temperatures studied in Experiment A, the main fracture mechanism detected is brittle fracture in the surrounding of the master alloy particles (Figs. 3 and 4).

When sintering at $1120^{\circ} \mathrm{C}$ (Fig. 3), decohesion facets are found due to degradation of grain boundaries by the presence of oxide inclusions and/or oxide layers. Thin oxide layers on grain boundaries cannot be detected by applied techniques. Decohesive facets present oxide inclusions with high $\mathrm{Mn}$ and Si content (P2 in Fig. 3).

Enhanced removal of oxides at high sintering temperatures (Fig. 4) reduces the amount of oxide inclusions in the grain boundaries. Therefore, decohesion facets turns to cleavage in samples sintered at $1250^{\circ} \mathrm{C}$. Cleavage is located in the highly alloyed areas where harder microstructures were developed.

Secondary pores left after melting/dissolution are covered by sponge-like residues (P3 in Fig. 3 and P3 in Fig. 4). Chemical composition of these residues is similar at both sintering temperatures but the shape and distribution changes significantly with temperature. After sintering at $1120^{\circ} \mathrm{C}$ residues are found all over the surface of the pores left by the master alloy. However, when sintering at $1250^{\circ} \mathrm{C}$ residues are usually concentrated in specific areas and acquire rounded morphologies.

On the fracture surface of the sample sintered at $1250^{\circ} \mathrm{C}$ the surface of the pore left by the master alloy is not completely covered by sponge-like residues and the smooth surface of the pore is visible (P4 in Fig. 4). EDS analyses on these smooth surfaces show high oxygen content combined with high amounts of $\mathrm{Mn}$ and $\mathrm{Si}$, presenting a $\mathrm{Mn} / \mathrm{Si}$ atomic ratio close to $1 / 1$. Due to the presence of oxidation sensitive elements, dissolution of oxygen in the liquid master alloy is favored. Oxygen dissolved in the liquid can recombine and forms a stable $\mathrm{Mn}$-Si oxide layer that stays in the pore surface after liquid phase solidifies. Such $\mathrm{Mn}$-Si oxide layer was also observed in samples sintered at $1120^{\circ} \mathrm{C}$ (see cross section in Fig. 2).

\subsubsection{Experiment $B$ : effect of sintering atmosphere}

This study is meant to evaluate the effect of the atmosphere when sintering is carried out at high temperatures $\left(1300^{\circ} \mathrm{C}\right)$. Due to the lower cooling rate applied in the dilatometer, samples from Experiment B present predominantly fine pearlitic microstructures (Fig. 5). Melting of master alloy particles seems to be incomplete, even though the sintering temperature is higher than in Experiment A.

The lower heating rates used in the dilatometer facilitate the oxygen transfer from the iron base powder to the surface of the master alloy particles. Incipient melting taking place in the master alloy surface incites dissolution of surface oxides. Likewise, changes in the composition of the surface during melting may encapsulate the master alloy particles and hinder the formation and distribution of the liquid.

Martensitic areas are occasionally found surrounding the location of primary master alloy particles, where a high concentration in alloying elements is expected. These highly alloyed areas seem to be broader in steels sintered in $\mathrm{H}_{2}$. Enhanced reduction of oxides in $\mathrm{H}_{2}$ provides better conditions

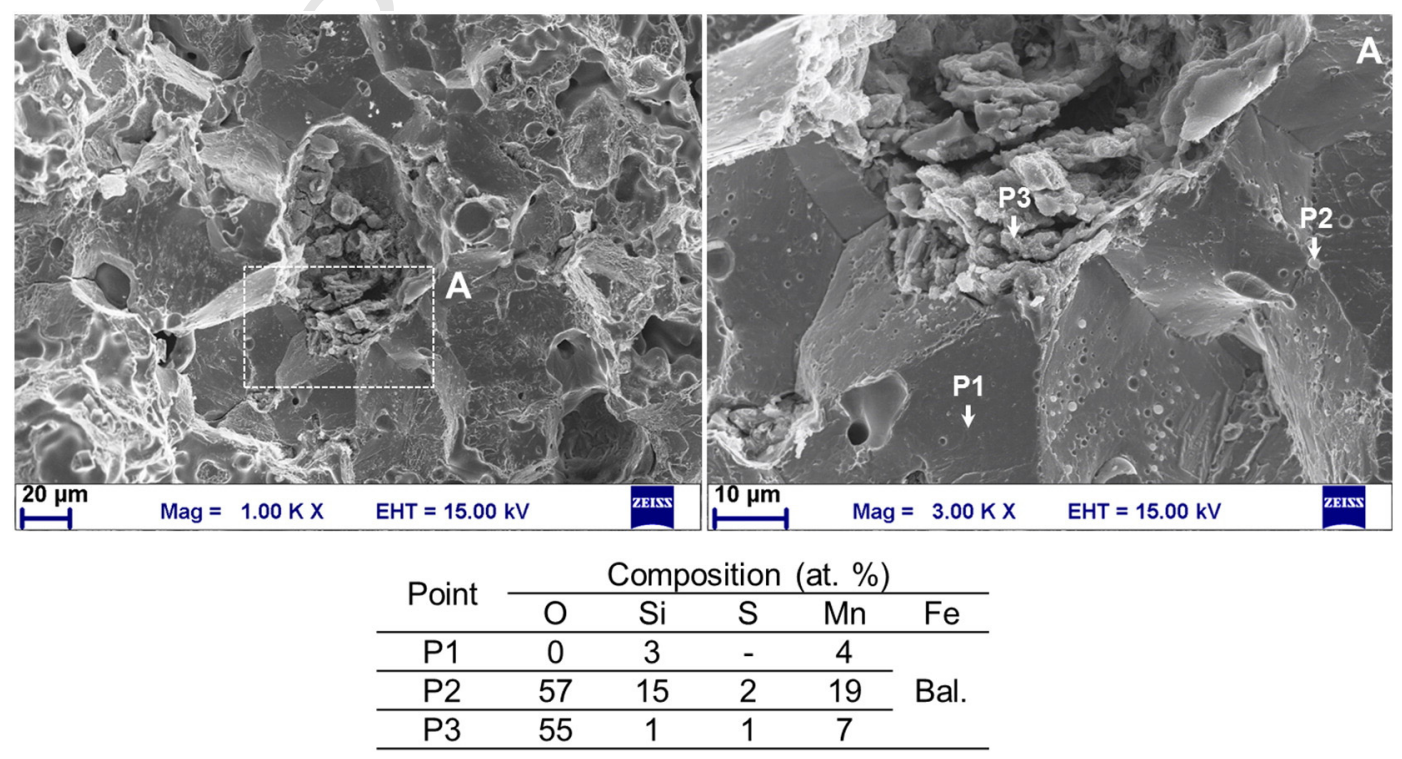

Fig. 3 - Detail of the fracture surfaces of steels sintered in $\mathrm{N}_{2}-10 \mathrm{H}_{2}-0.1 \mathrm{CH}_{4}$ at $1120{ }^{\circ} \mathrm{C}$ (Experiment A). 

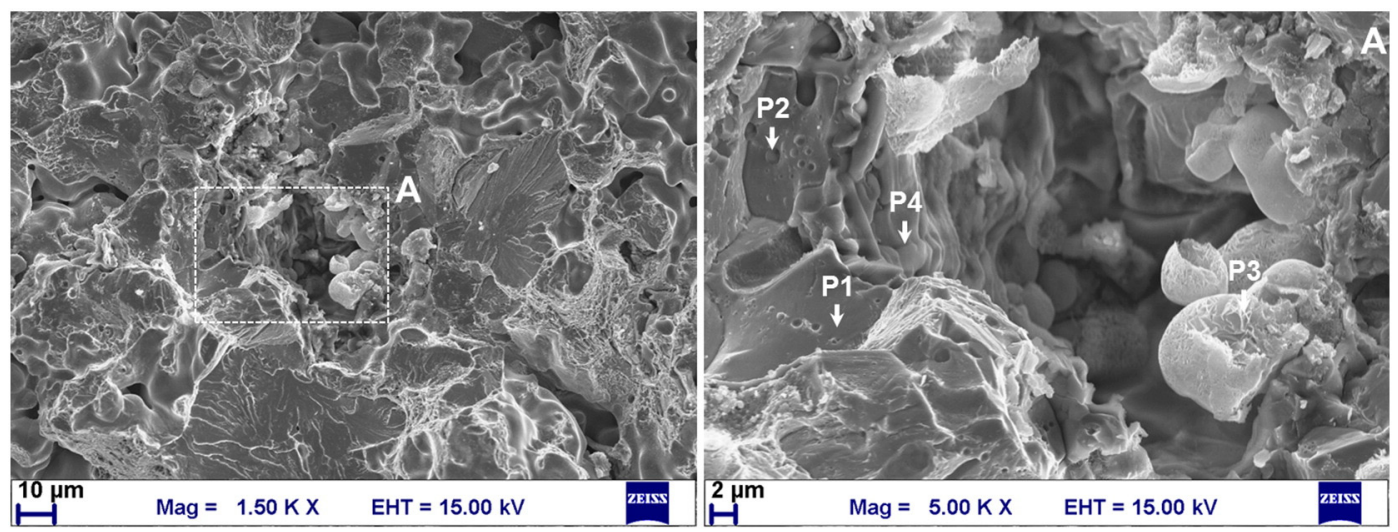

\begin{tabular}{cccccc} 
& \multicolumn{5}{c}{ Composition (at. \%) } \\
\cline { 2 - 5 } Point & O & Si & S & Mn & Fe \\
\hline P1 & 6 & 4 & - & 4 & \\
P2 & 50 & 15 & 1 & 17 & \multirow{2}{*}{ Bal. } \\
\hline P3 & 67 & 2 & 1 & 8 & \\
\hline P4 & 65 & 16 & - & 15 & \\
\hline
\end{tabular}

Fig. 4 - Detail of the fracture surfaces of steels sintered in $\mathrm{N}_{2}-10 \mathrm{H}_{2}-0.1 \mathrm{CH}_{4}$ at $1250{ }^{\circ} \mathrm{C}$ (Experiment A).

for wetting and promotes distribution of the liquid phase and diffusion of alloying elements present in the liquid master alloy.

Areas with a light gray contrast around the master alloy particles correspond to mixed Mn-Si oxides. It is not possible to determine whether these oxides form a continuous layer on the surfaces, since they can be partly dissolved in the etching agent used for revealing bainitic and martensitic microstructures.

Fracture surfaces of steels from Experiment B show that, regardless of the sintering atmosphere used, the dominant

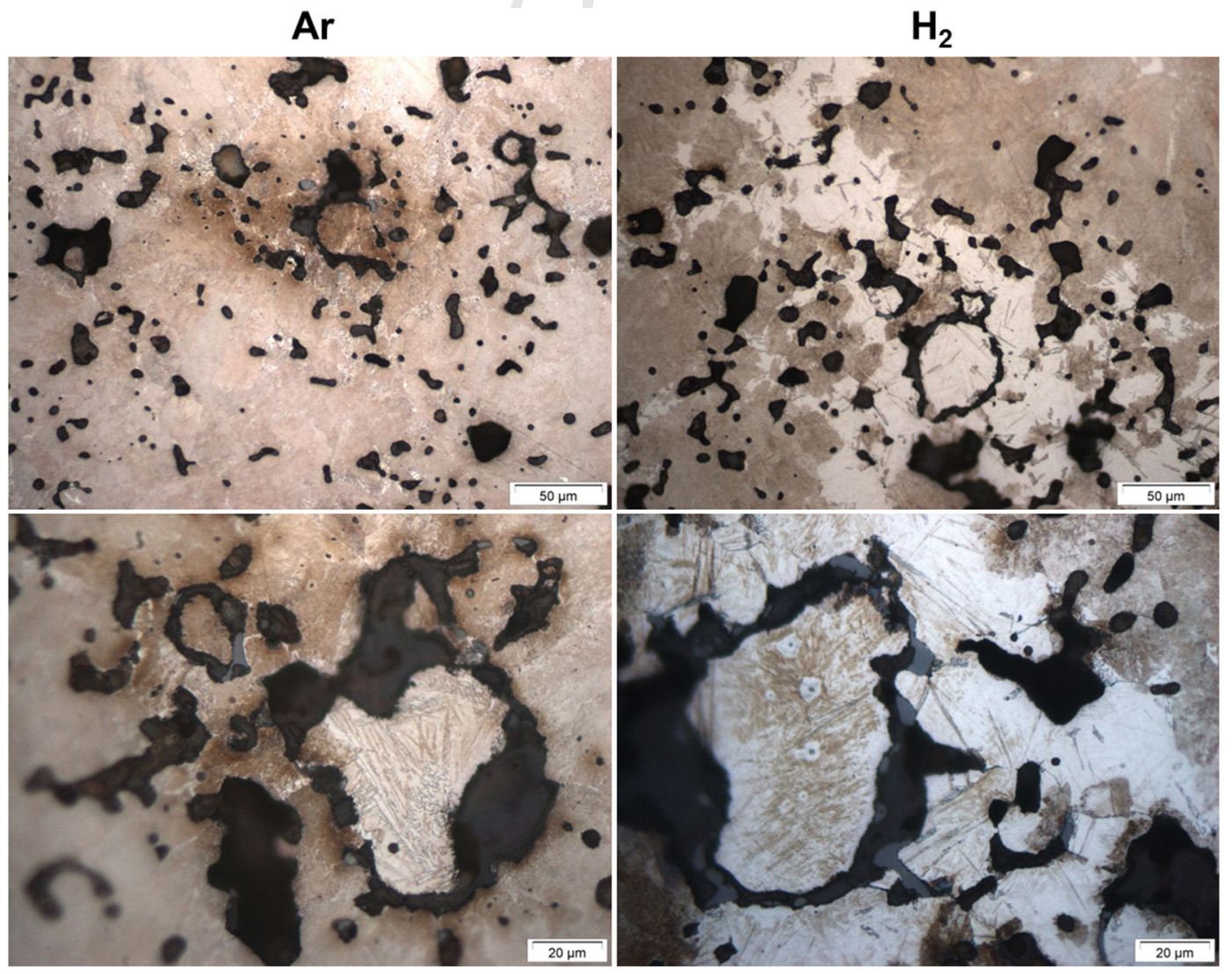

Fig. 5 - Microstructure of steels sintered in the dilatometer at $130{ }^{\circ} \mathrm{C}$ for $1 \mathrm{~h}$ in $\mathrm{Ar}$ (left) and $\mathrm{H}_{2}$ (right). 
mechanism of failure is brittle fracture in the surrounding of the master alloy particles, consisting of decohesive failure along the grain boundaries surrounded by areas of cleavage (Fig. 6-H2, Fig. 7-Ar).

Although intergranular facets are observed in both $\mathrm{H}_{2}$ and Ar sintered samples, an increase in cleave patterns is found in reducing atmosphere. Oxide inclusions have considerably larger sizes in samples sintered in Ar (see, for instance P2, P4 and $\mathrm{P} 5$ in Fig. 7), which favors decohesive failure. EDS analyses performed on these oxides (P2 Fig. 6 and P2, P3, P4, P5 Fig. 7) reveal high $\mathrm{Mn}$ and $\mathrm{Si}$ content with a $\mathrm{Mn} / \mathrm{Si}$ atomic ratio close to $1 / 1$.

The surface of the secondary pore left after melting of the master alloy particles is also here covered by residues. Residues found on the different surfaces present a sponge-like rounded morphology and are covering the surfaces as an oxide crust (P3 in Fig. 6 and P6, P7 in Fig. 7). Residues with sponge-like morphology were found in both sintering atmospheres; however, $\mathrm{H}_{2}$-sintering provides cleaner fracture surfaces. Analyses on sponge-like residues show high oxygen content, variable amounts of $\mathrm{Mn}$, some S, and very low content (if any) of the strongest oxide former, $\mathrm{Si}$.

On the fracture surfaces of the samples sintered in $\mathrm{H}_{2}$, areas with evidences of liquid phase presence were found (P4 in Fig. 6) where EDS analyses suggest that it consist mainly of $\mathrm{Mn}-\mathrm{S}$ compound.

The surfaces of the pores located nearby the master alloy particles (Fig. 8) are covered by condensed oxides. Similar features have been previously observed when $\mathrm{Mn}$ was added as ferromanganese or in electrolytic form, and it was attributed to the oxidation of evaporated $\mathrm{Mn}$ and subsequent condensation on the surrounding pore surfaces $[29,30]$. Significantly lower amounts of such oxides were found in $\mathrm{H}_{2}$ sintered samples as a consequence of the enhanced reduction of iron oxides at temperatures where $\mathrm{Mn}$ evaporation is still negligible $\left(\sim 400^{\circ} \mathrm{C}\right)$. Under Ar atmosphere, carbothermal reduction of iron oxides at higher temperatures (around $700{ }^{\circ} \mathrm{C}$ ) is promoting oxidation of Mn vapor which condensates forming oxides.

\subsection{XPS analyses on the fracture surfaces}

Fig. 9 shows the XPS survey spectra of the fresh fracture surfaces in steels modified with master alloy additions. All of the fracture surfaces studied contained Fe, O, C, Mn, S and Si. In steels sintered in $\mathrm{N}_{2}-10 \mathrm{H}_{2}$ (Experiment $\mathrm{A}$ ) traces of $\mathrm{N}$ are present due to some nitrogen pickup from the sintering atmosphere. Steels sintered at $1300{ }^{\circ} \mathrm{C}$ (Experiment B) show small amounts of $\mathrm{Ca}$ that might be present as traces in the original powders and segregates at the surface at high temperatures.

Since the residues found on the fracture surfaces were generally rich in oxygen and/or sulfur the concentration depth profile for these elements is represented in Fig. 10.

Oxygen enrichment is detected in all of the fracture surfaces studied, and the oxygen depth profile is symmetrical for steels belonging to the same group (Experiment A or Experiment B). Increasing the sintering temperature in samples sintered in $\mathrm{N}_{2}-10 \mathrm{H}_{2}$ the bulk oxygen content decreases due to enhanced reduction of the oxides.

Likewise, in samples sintered at $1300^{\circ} \mathrm{C}$, bulk oxygen content is lower for samples sintered in $\mathrm{H}_{2}$ atmosphere. As
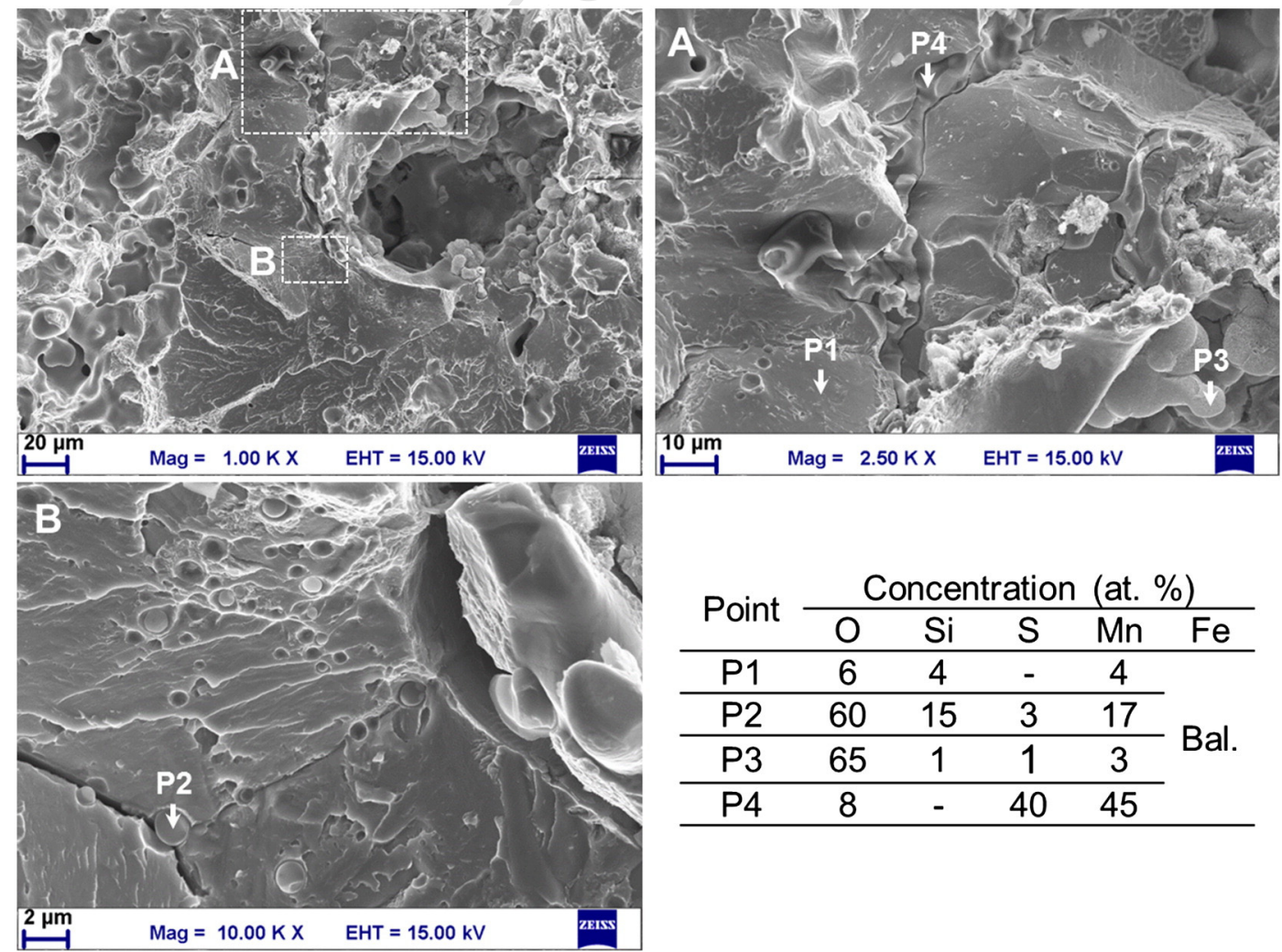

\begin{tabular}{|c|c|c|c|c|c|}
\hline \multirow{2}{*}{ Point } & \multicolumn{5}{|c|}{ Concentration (at. \%) } \\
\hline & $\mathrm{O}$ & $\mathrm{Si}$ & $\mathrm{S}$ & $\mathrm{Mn}$ & $\mathrm{Fe}$ \\
\hline $\mathrm{P} 1$ & 6 & 4 & - & 4 & \\
\hline $\mathrm{P} 2$ & 60 & 15 & 3 & 17 & \\
\hline P3 & 65 & 1 & 1 & 3 & Bal. \\
\hline P4 & 8 & - & 40 & 45 & \\
\hline
\end{tabular}

Fig. 6 - Detail of the fracture surface of steel sintered in $\mathrm{H}_{2}$ in the dilatometer at $1300{ }^{\circ} \mathrm{C}$ (Experiment B). 

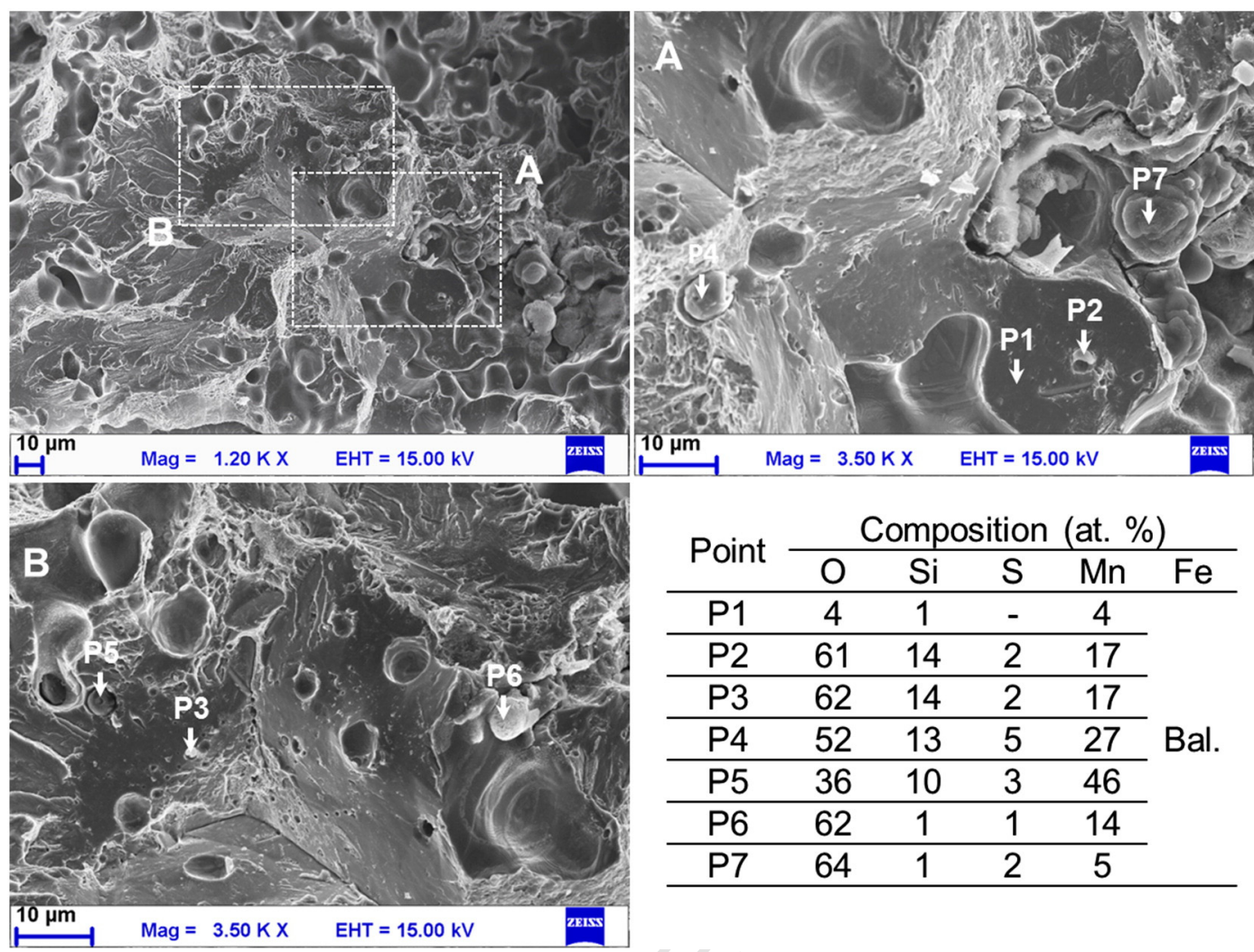

\begin{tabular}{cccccc}
\multirow{2}{*}{ Point } & \multicolumn{5}{c}{ Composition (at. \%) } \\
\cline { 2 - 5 } & $\mathrm{O}$ & $\mathrm{Si}$ & $\mathrm{S}$ & $\mathrm{Mn}$ & $\mathrm{Fe}$ \\
\hline P1 & 4 & 1 & - & 4 & \\
\cline { 1 - 5 } P2 & 61 & 14 & 2 & 17 & \\
\hline P3 & 62 & 14 & 2 & 17 & \\
\cline { 1 - 5 } P4 & 52 & 13 & 5 & 27 & Bal. \\
\cline { 1 - 5 } P5 & 36 & 10 & 3 & 46 & \\
\hline P6 & 62 & 1 & 1 & 14 & \\
\hline P7 & 64 & 1 & 2 & 5 & \\
\hline
\end{tabular}

Fig. 7 - Detail of the fracture surface of steel sintered in Ar in the dilatometer at $1300{ }^{\circ} \mathrm{C}$ (Experiment B).

expected, oxide reduction seems to be promoted both by high sintering temperatures and by the use of reducing atmospheres.

Regarding the sulfur content, no differences are registered when increasing the temperature from $1120^{\circ} \mathrm{C}$ to $1250{ }^{\circ} \mathrm{C}$ in the samples sintered in $\mathrm{N}_{2}-10 \mathrm{H}_{2}$. Samples sintered at $1300{ }^{\circ} \mathrm{C}$ in the dilatometer show very higher sulfur contents on the fracture surface, particularly high for those sintered in Ar. This is in agreement with the higher amount of residues (oxides/sulfides) found by SEM examination in the surface of the Ar sintered samples.

The XPS narrow scan over the binding energies of S2p is presented in Fig. 11 where the binding energies of the different chemical states for sulfur are indicated: $S^{0}, S^{2-}$ and $\mathrm{SO}_{4}^{2-}$. Sulfur is mainly present on the surfaces as $\mathrm{S}^{2-}$ or in its atomic form $\mathrm{S}^{0}$. Although no significant differences were found in the sulfur content registered in the samples sintered at $1120^{\circ} \mathrm{C}$ and $1250{ }^{\circ} \mathrm{C}$, the spectra show how an increase in the sintering temperature slightly increases the contribution of $\mathrm{S}^{2-}$. This means that, at higher temperatures sulfur is more likely combined forming sulfides.

Sintering at $1300{ }^{\circ} \mathrm{C}$ in the dilatometer provides higher intensities of the $\mathrm{S}^{2-}$ peak, especially for the samples sintered in Ar. Besides, sulfur in $\mathrm{SO}_{4}^{2-}$ state is detected in both samples sintered at $1300{ }^{\circ} \mathrm{C}$. The presence of $\mathrm{SO}_{4}^{2-}$ has been previously
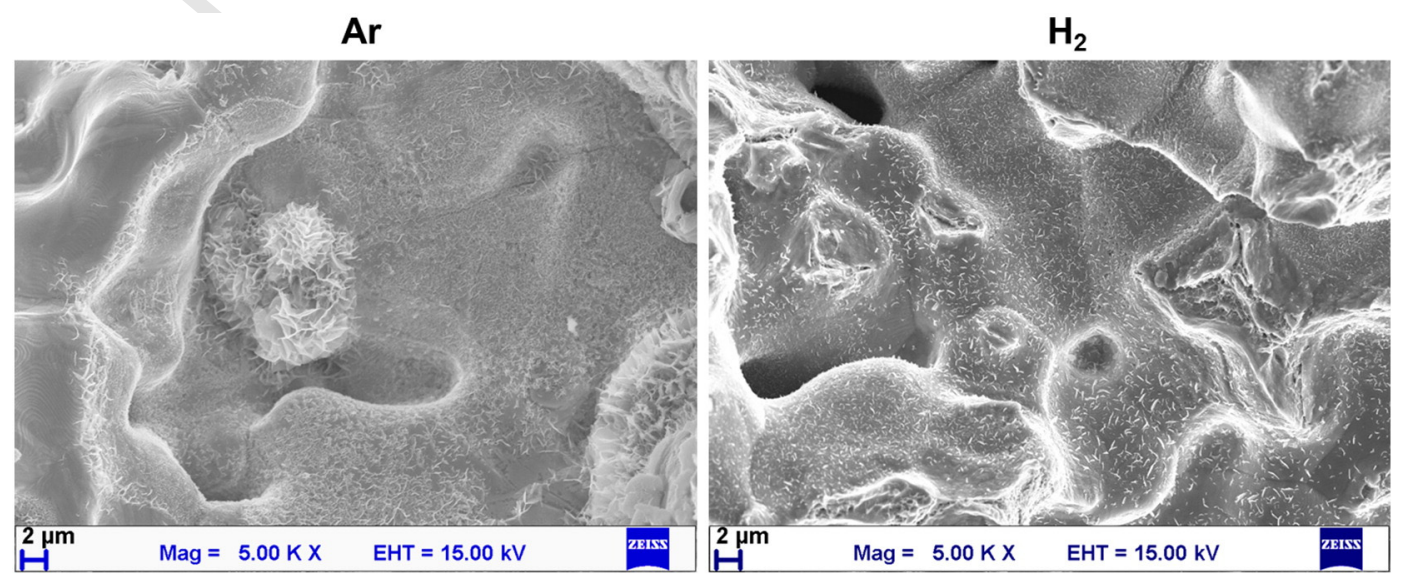

Fig. 8 - Surface of the pores surrounding the master alloy particles. Left: Ar, Right: $\mathrm{H}_{2}$. 


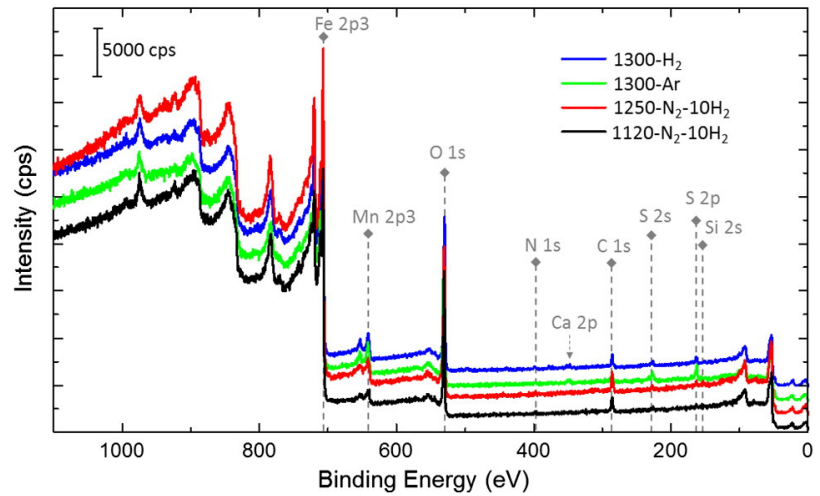

Fig. 9 - XPS survey spectra on the fracture surface of sintered steels.

reported for $\mathrm{Mn}$ containing steels where it was proved that exposure of the system $\mathrm{Mn}-\mathrm{S}$ to oxygen containing atmosphere leads to preferable formation of $\mathrm{MnSO}_{4}$ [31] on the surface of MnS.

3.4. Model for microstructure development and the oxide distribution during sintering

Microstructure evolution during sintering can affect significantly the distribution and morphology of the oxides present in the final sintered part. Based on the results presented in this study, the model exposed in Fig. 12 is proposed for explaining the evolution of microstructure and oxide formation in the surrounding of the master alloy particles.

Stage I (From the beginning of sintering to incipient melting of master alloy particles $\sim 1000{ }^{\circ} \mathrm{C}$ ):

Both iron and master alloy powders are naturally covered by oxides. Such oxides typically consist mainly on an iron oxide layer with inclusions of more stable oxides. The iron oxide layer can be reduced at moderate temperatures at which reduction of $\mathrm{Mn}$ and $\mathrm{Si}$ oxides is still not possible. This leads to an oxygen transfer from the iron oxide layers to the oxidation sensitive metallic elements mainly available in the surface of the master alloy particles. The

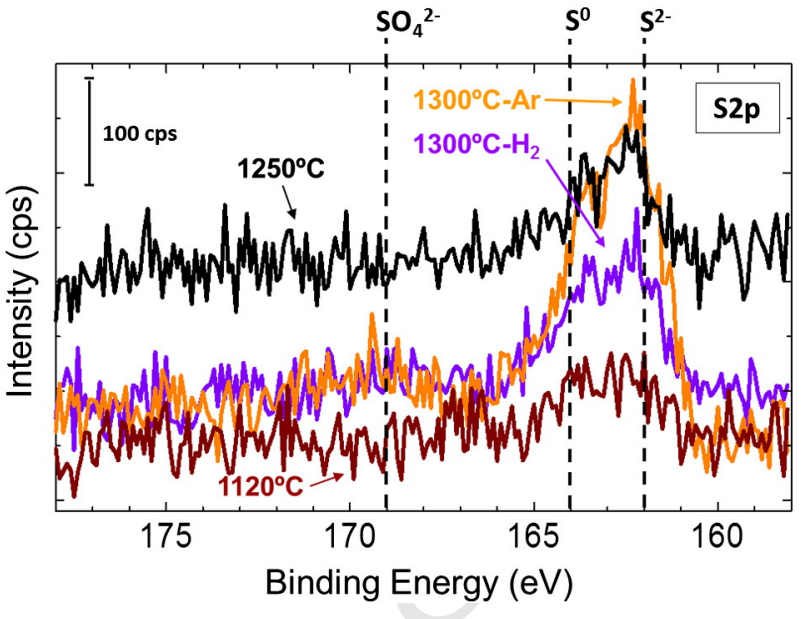

Fig. 11 - XPS spectra over the binding energies of S2p.

more intense is the oxygen transfer, the more oxygen is concentrated on the surface of the master alloy particles. When incipient liquid phase formation takes place on the master alloy surface, such surface oxides might be at least partly dissolved in the liquid.

Manganese evaporation starts at temperatures above $700^{\circ} \mathrm{C}$. Manganese vapor penetrates through surrounding porosity and iron grain boundaries, enhancing its distribution within the compact. However, at temperatures around $700-1000{ }^{\circ} \mathrm{C}, \mathrm{Mn}$ is still avid for oxygen and therefore it will react and condensate on the different surfaces in the form of oxides or sulfides [30]. This phenomenon is responsible for the formation of characteristic condensed oxides observed in Fig. 8, and is more intense when sintering in Ar atmospheres.

Stage II (From incipient melting of master alloy particles until complete dissolution of transient liquid phase):

Master alloy particles melt progressively in a temperature range of approximately $20^{\circ} \mathrm{C}$ [22]. Liquid master alloy dissolves the surface of the iron base particles, which improves its wetting behavior and facilitates its distribution over the iron surfaces. Once the liquid is saturated in iron, re-solidification takes place and the liquid phase finally disappears. Dissolution of iron particles surface followed by subsequent re-solidification closes the pore

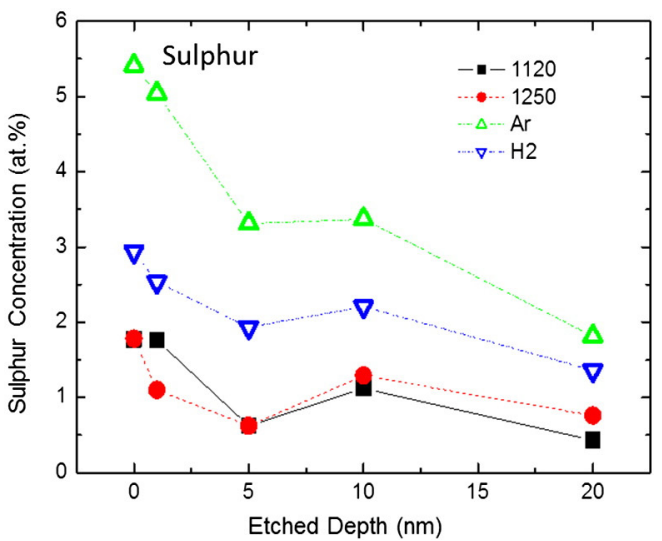

Fig. 10 - Oxygen and sulfur content (at.\%) on the fracture surface of sintered steels. 


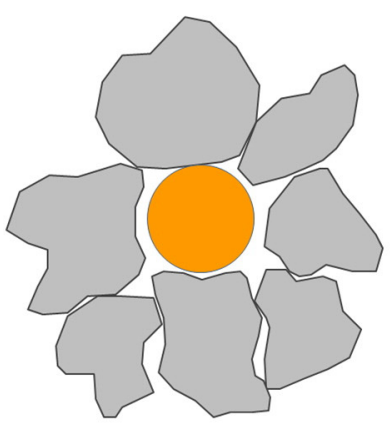

Stage I

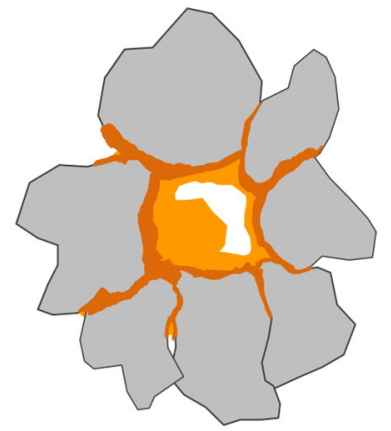

Stage II

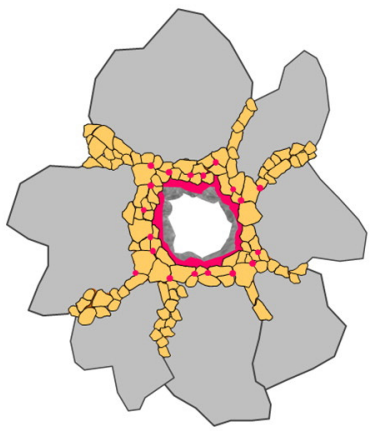

Stage III

Fig. 12 - Mechanism of microstructure development and oxides evolution when sintering steels modified with Fe-Mn-Si-C master alloy additions.

channels in the surrounding of the master alloy particles [22,32], favoring the formation of a micro-climate inside the secondary pore left by the master alloy particle.

The liquid master alloy continuously changes its composition due to the diffusion of alloying elements and the dissolution of the iron base particles. Likewise, oxides present on the surface of the master alloy particles or the iron base particles are dissolved in the liquid. The more oxides are present on the different powder surfaces (and especially on the master alloy surface), the more oxygen will be dissolved in the liquid. Oxygen dissolved in the liquid will recombine with oxidation sensitive elements and form a layer of stable oxides on top of the liquid (such as those shown in Figs. 2 and 4). This oxide layer is difficult to detect after metallographic preparation since it is easily dissolved in the etching agents, but its presence is evidenced in fractography studies.

Stage III (After re-solidification of the liquid phase):

Once the transient liquid phase disappears, diffusion of alloying elements takes place in the solid state. Due to the high $\mathrm{Mn}$ and Si content in the surrounding of the master alloy particles, selective oxidation of these elements occurs preferentially on the grain boundaries of the particles surrounding the location of original master alloy particles. Oxide inclusions degrade the grain boundaries and are responsible for intergranular failure detected in these steels.

An increase in sintering temperature considerably decreases the amount of such oxide inclusions. This is evidenced by the improvement in inter-particle contacts observed in Fig. 1 and the reduction of decohesive facets on the fracture surface from $1120^{\circ} \mathrm{C}$ (Fig. 3) to $1250{ }^{\circ} \mathrm{C}$ (Fig. 4).

Sintering atmosphere was found to affect importantly the size and amount of oxide inclusions, which are considerably larger when sintering in Ar (Fig. 7). Enhanced oxygen transference in Ar atmospheres leaves higher oxygen contents trapped in the material, and seems to enhance growth of $\mathrm{Mn}-\mathrm{Si}$ oxides nucleated on grain boundaries. Hydrogen atmosphere allows reducing iron oxides at lower temperatures $\left(400^{\circ} \mathrm{C}\right)$ at which the master alloy is less reactive, which somehow alleviates the oxygen transfer.

Besides oxide inclusions in grain boundaries, oxides were also found in the form of residues, left on the secondary pores by the master alloy particles. Such residues are mainly of two types: continuous and homogeneous layers covering the pores or sponge-like oxides.

Continuous layers are most likely formed by selective oxidation of $\mathrm{Mn}-\mathrm{Si}$ on the surface of areas where liquid phase was present. When sintering in $\mathrm{H}_{2}$, such layers were found to contain mainly Mn and S, with negligible amounts of oxygen. This fact can be explained by the formation of MnS compounds on the surface of the $\mathrm{Mn}-\mathrm{Si}$ oxide. During cooling, solubility of $\mathrm{S}$ in the oxide decreases, and it segregates forming a MnS layer. This is especially evident at low cooling rates, as those applied in the dilatometer in Experiment $\mathrm{B}$.

Oxides with sponge like morphology seem to be formed by a condensation process. When the conditions are less reducing (low sintering temperatures and/or Ar atmosphere) such oxides are found covering completely the surface of the secondary pores. Generally, when improving the sintering conditions either by increasing the temperature or by using reducing atmospheres, sponge-like oxides are concentrated in specific areas and acquire a rounded morphology. Formation of spongelike oxides might be a consequence of the microclimate created inside the secondary pore due to closure of surrounding pore channels. In these conditions, the more oxygen is initially dissolved in the liquid, the higher the partial pressure of oxygen inside the pore and therefore the more important the oxidation-condensation phenomena on the surfaces of the secondary pore.

\section{Conclusions}

Microscopy, fractography, chemical analyses and surface 632 analysis techniques have been combined in this study to 633 propose a model for the microstructural development and for 634 the evolution of oxide distribution during sintering of steels 635 containing Fe-Mn-Si-C master alloys, considering the influ- 636 ence of sintering temperature and processing atmosphere. $\quad 637$

- Oxide reduction is enhanced by the use of high sintering 638 temperatures or reducing atmospheres. Due to the "internal- 639 getter" character of the master alloy particles, the use of high 640 heating rates at the early stages of sintering and reducing 641 agents with high efficiency at low temperatures $\left(\mathrm{H}_{2}\right)$ are 642 
critical for alleviating oxygen transfer to the surface of the master alloy particles, lowering the final oxygen content in the sintered steel.

- In steels containing Fe-Mn-Si-C master alloys the main mechanism of failure is decohesion and cleavage fracture in the surrounding of the master alloy particles. Brittle decohesion failure is caused by the degradation of the grain boundaries due to the presence of $\mathrm{Mn}-\mathrm{Si}$ oxide inclusions. The fraction of such intergranular decohesion facets around master alloy particles decreases and is substituted with increasing portions of cleavage facets when increasing sintering temperature or when using reducing atmospheres (because the size and amount of oxide inclusions in grain boundaries decreases).

- Particulate oxide inclusions are formed by selective oxidation of $\mathrm{Mn}$ and $\mathrm{Si}$ in the grain boundaries of the $\mathrm{Mn}-\mathrm{Si}$ rich areas where the formation of $\mathrm{Mn}-\mathrm{Si}$ mixed oxides is favored. Due to the dissolutive behavior of the liquid phase used, both oxygen and the oxygen-sensitive elements present in the liquid phase remain concentrated in the surrounding of the original master alloy particles and therefore this areas present higher amount of oxide inclusions. Formation of acicular ferrite might be possible in these steels under specific conditions: high sintering temperatures that promote $\mathrm{MnS}$ segregation on the surface of $\mathrm{Mn}$ :Si oxide inclusions, and relatively rapid cooling rates $\left(0.75^{\circ} \mathrm{C} / \mathrm{s}\right)$.

- Relatively high sulfur content is detected on the fracture surface after sintering and its presence is usually associated with high oxygen content areas. MnS layers seem to grow preferentially on the surface of $\mathrm{Mn}$-Si mixed oxides, especially when high sintering temperatures and low cooling rates are applied.

- High sintering temperatures $\left(\geq 1250{ }^{\circ} \mathrm{C}\right)$ and reducing atmospheres provide the best conditions for sintering $\mathrm{Mn}-\mathrm{Si}$ steels, since the "internal getter" effect of the master alloy particles is somehow minimized by the reduction of iron oxides at lower temperatures where the reactivity of the master alloy is still not so high. Special attention must be paid to the evolution of the Mn-Si particulate oxides formed on the iron grain boundaries which might strongly deteriorate mechanical properties of $\mathrm{Mn}$-Si steels.

\section{Acknowledgments}

The authors wish to thank C. Gierl and H. Danninger from the Technical University of Vienna Austria for their assistance in processing sintered steels. The financial support provided by the Höganäs AB Sweden is gratefully acknowledged.

\section{R E F E R E N C E S}

[1] Albano-Müller L, Thümmler F, Zapf G. High-strength sintered iron-base alloys by using transition metal carbides. Powder Metall 1973;16:236-56.

[2] Hoffmann G, Dalal K. Development and present situation of low alloyed PM steels using MCM and MVM master alloys. Powder Metall Int 1979:177-80.
[3] Schlieper G, Thümmler F. High strength heat-treatable sintered steels containing manganese, chromium, vanadium and molybdenum. Powder Metall Int 1979;172:174-6.

[4] Zapf G, Dalal K. Introduction of high oxygen affinity elements manganese, chromium and vanadium in the powder metallurgy of P/M parts. Mod Dev Powder Metall 1977:129-52.

[5] Klein AN, Oberacker R, Thümmler F. High-strength Si-Mn-alloyed sintered steels - microstructure and mechanical-properties. Powder Metall Int 1985;17:13-6.

[6] Klein AN, Oberacker R, Thümmler F. High-strength Si-Mn-alloyed sintered steels - sinterability and homogenization. Powder Metall Int 1985;17:71-4.

[7] Klein AN, Oberacker R, Thümmler F. Development of new high strength Si-Mn-alloyed sintered steels. Mod Dev Powder Metall 1985;16:141-52.

[8] PhD Thesis:Oro R. Diseño de Aleaciones Maestras para la Sinterización en Fase Líquida de Aceros al Mn-Si. Madrid, Spain: Department of Materials Science and Engineering, Universidad Carlos III de Madrid; 2012.

[9] Oro R, Campos M, Gierl C, Danninger H, Torralba JM. Atmosphere effects on liquid phase sintering of PM steels modified with master alloy additions. In: S. European Powder Metallurgy Association, editor. M2010 Powder Metallurgy World Congress \& Exhibition. Shrewsbury, Florence: European Powder Metallurgy Association; 2010. p. 275-82.

[10] Danninger H, Jaliliziyaean M, Gierl C, Hryha E, Bengtsson S. Sintered steels prealloyed with manganese - chances and risks. In: EPMA, editor. Proceedings EuroPM2010. Flocence: EPMA; 2010.

[11] Kim HS, Lee HG, Oh KS. MnS precipitation in association with manganese silicate inclusions in $\mathrm{Si} / \mathrm{Mn}$ deoxidized steel. Metall Mater Trans A 2001;32:1519-25.

[12] Kim HS, Lee HG, Oh KS. Evolution of size, composition, and morphology of primary and secondary inclusions in Si/Mn and Si/Mn/Ti deoxidized steels. ISIJ Int 2002;42:1404-11.

[13] Lepera FS. Improving etching technique to emphasize martensite and bainite in high strength dual-phase steel. J Met 1980;32:38-9.

[14] Moulder J, Stickle W, Sobol P, Bomben K. Handbook of X-ray Photoelectron Spectroscopy; 1992.

[15] Nyborg L, Nylund A, Olefjord I. Thickness determination of oxide layers on spherically-shaped metal powders by ESCA. Surf Interface Anal 1988;12:110-4.

[16] Olefjord I, Nyborg L. Surface-analysis of gas atomized ferritic steel powder. Powder Metall 1985;28:237-43.

[17] Danninger H, Gierl C. Processes in PM steel compacts during the initial stages of sintering. Mater Chem Phys 2001;67:49-55.

[18] Danninger H, Gierl C. New alloying systems for ferrous powder metallurgy precision parts. Sci Sinter 2008;40:33-46.

[19] Danninger H, Gierl C, Kremel S, Leitner G, Jaenicke-Roessler $\mathrm{K}, \mathrm{Yu} \mathrm{Y}$. Degassing and deoxidation processes during sintering of unalloyed and alloyed PM steels. Powder Metall Prog 2002;2:125-40.

[20] Lee SM, Kang SJL. Microstructure development during liquid-phase sintering. Z Metallkd 2005;96:141-7.

[21] Dlapka M, Danninger H, Gierl C, Klammer E, Weiss B, Khatibi G, Betzwar-Kotas A. Fatigue behavior and wear resistance of sinter-hardening steels. Int J Powder Metall 2012;48:49-60.

[22] Oro R, Campos M, Torralba JM, Capdevila C. Lean alloys in PM: from design to sintering performance. Powder Metall 2012;55:294-301.

[23] J. In-Ho, Overview of the applications of thermodynamic databases to steelmaking processes, Calphad, 34 332-362.

[24] Liu Z, Kobayash Y, Yin F, Kuwabara M, Nagai K. Nucleation of acicular ferrite on sulfide inclusion during rapid solidification of low carbon steel. ISIJ Int 2007;47:1781-8.

[25] Cvijovic I, Parezanovic I, Spiegel M. Influence of $\mathrm{H}_{2}-\mathrm{N}_{2}$ atmosphere composition and annealing duration on the 
selective surface oxidation of low-carbon steels. Corros Sci 2006;48:980-93.

[26] Ollivier-Leduc A, Giorgi ML, Balloy D, Guillot JB. Nucleation and growth of selective oxide particles on ferritic steel. Corros Sci 2010;52:2498-504.

[27] Suzuki Y, Yamashita T, Sugimoto Y, Fujita S, Yamaguchi S. Thermodynamic analysis of selective oxidation behavior of $\mathrm{Si}$ and Mn-added steel during recrystallization annealing. ISIJ Int 2009;49:564-73.

[28] Swaminathan S, Spiegel M. Thermodynamic and kinetic aspects on the selective surface oxidation of binary, ternary and quarternary model alloys. Appl Surf Sci 2007;253:4607-19.
[29] Hryha E, Dudrova E, Nyborg L. Critical aspects of alloying of sintered steels with manganese. Metall Mater Trans A 2010;41A:2880-97.

[30] Hryha E, Dudrova E. The sintering behaviour of Fe-Mn-C powder system, correlation between thermodynamics and sintering process, Mn distribution, and microstructure. Prog Powder Metall 2007;534-536:761-4 (Pts 1 and 2).

[31] Hryha E, Gierl C, Nyborg L, Danninger H, Dudrova E. Surface composition of the steel powders pre-alloyed with manganese. Appl Surf Sci 2010;256:3946-61.

[32] Oro R, Campos M, Torralba JM. Study of high temperature wetting and infiltration for optimising liquid phase sintering in low alloy steels. Powder Metall 2012;55:180-90. 